\title{
A Teoria do Agir Comunicativo e a FormaÇÃo MÉdicA: ANÁlise CRÍTICA DAS COMPETÊNCIAS CURRICULARES E DA RELAÇÁO MÉDICO-PACIENTE
}

\author{
The Theory of Communicative Action and Medical \\ EDUCATION: CRITICAL ANALYSIS OF CURRICULUM SKILLS AND \\ PHYSICIAN-PATIENT RELATIONSHIP
}

\begin{abstract}
Antonio da Silva Menezes Junior Doutor em Ciências da Saúde pela Universidade de São Paulo. Professor do Programa de Pós-graduação Stricto Sensu em Educação da Pontifica Universidade Católica de Goiás. Goiânia - GO - Brasil a.menezes.junior@uol.com.br

Iria Brzezinski

Doutora em Educação pela Universidade de São Paulo. Professora Titular da Pontifícia Universidade Católica de Goiás. Goiânia - GO - Brasil iriaucg@yahoo.com.br
\end{abstract}

\begin{abstract}
Resumo: Trata-se de uma pesquisa qualitativa, de cunho teórico, com base na Teoria do Agir Comunicativo, de Habermas. As categorias analisadas são: linguagem (construção coletiva de identidade), ação comunicativa (razão comunicativa), trabalho, interação e poder (ação instrumental), mundo do sistema e mundo da vida. As políticas de formação desses profissionais (mundo do sistema), oriundas de um modelo desagregado do contexto social e cultural (mundo objetivo) e voltadas ao mercado do trabalho, distanciam-se do mundo subjetivo habermasiano. Destoam, também, da formação omnilateral necessária para a transformaçáo e a inserção social no contexto de uma modernidade tardia. As políticas instituídas reproduzem o modelo neoliberal quando não agregam a possibilidade de inclusão do outro e não estabelecem a possibilidade do diálogo como processo de (re) construção das relaçóes humanas, em especial da relação médico-paciente e do trabalho em equipe multiprofissional.
\end{abstract}

Palavras-chave: Formação Médica. Pesquisa Qualitativa. Políticas curriculares. Relação Médico-Paciente. Teoria do Agir Comunicativo.

Abstract: This is a qualitative research, based on the Theory of Communicative Action of Habermas. The categories analysed are: language (collective construction of identity), communicative action (communicative reason), work, interaction and power (instrumental action), the system world and the world of life. The training policies of these professionals (system world), derived from a disaggregated model of the social and cultural context (objective world) and focused on the labor market, are distanced from the Habermasian subjective world. They are also distanced from the omnilateral formation necessary for social transformation and insertion in the context of a late modernity. The policies instituted reproduce the neoliberal model, when they do not add the possibility of inclusion of the other 
and do not establish the possibility of dialogue as a process of (re) construction of human relations, especially the doctor-patient relationship and multiprofessional teamwork.

Keywords: Medical Training. Qualitative Research. Curricular Policies. Physician-Patient Relationship. Theory of Communicative Action.

\section{Introduçáo}

Neste artigo tem-se o propósito de apresentar a teoria do agir comunicativo, de Jürgen Habermas, como relevante para as relaçóes humanas. A teoria surge a partir da existência de estruturas de racionalidade já desenvolvidas em âmbito cultural, além das representaçôes legais e morais contidas nas visōes de mundo e que permitem organizar os sistemas de ação configurados em novos níveis de integração social. Habermas (1987a), no que se refere à valorizaçáo da técnica pela técnica e da técnica como ideologia, nos ensina que importa recuperar e preservar, no espaço público da escola, a interatividade da razão comunicativa inscrita no Mundo da Vida para, a partir desse balizador, combater déficits racionais vigentes no paradigma pedagógico da modernidade tardia e, assim, formar cientistas e técnicos competentes, mas com outra "alma", e, portanto, médicos reflexivos e políticos capazes de conduzir honesta e eticamente a saúde pública, compromissados com a democracia e com a inclusão do outro.

Objetiva-se assumir a razão comunicativa como referencial teórico, visando refletir sobre o distanciamento existente entre a formação humanista e as políticas neoliberais. Enquanto a formaçáo humanista surge como proposta das resoluçōes do Conselho Nacional de Educação (CNE) e da Câmara de Ensino Superior (CES) - Resolução CNE/CES no 4, de 9 de novembro de 2001 (BRASIL, 2001), e Resoluçáo CNE/CES no 3, de 20 de junho de 2014 (BRASIL, 2014) -, as políticas liberais provocam a fragmentaçáo do conhecimento profissional do médico requerido pelo mercado de trabalho. Esses profissionais deveriam estar inseridos no mundo objetivo-subjetivo do trabalho, na busca de transformação, de emancipaçáo social, e, suspostamente, afastados do individualismo imposto pelo modelo neoliberal. Entende-se como modelo neoliberal a adoção do Estado mínimo regulado pelas relaçôes de produção e sem a garantia de recursos financeiros para as políticas sociais, visto que esse Estado atende aos interesses das classes dominantes. 
Quanto à abordagem metodológica, desenvolve-se uma pesquisa qualitativa, de caráter teórico, sustentada na Teoria do Agir Comunicativo, e uma análise documental das Diretrizes Curriculares Nacionais (DCN) do Curso de Medicina de 2001 e 2014. As categorias analisadas são: a linguagem (construção coletiva de identidade), a ação comunicativa (razão comunicativa), o trabalho, a interação e o poder (referem-se ao modo como a pessoa controla e manipula o seu ambiente - açáo instrumental), o mundo do sistema e o mundo da vida. Apesar de Habermas não abordar especificamente a Medicina, a sua escolha como referência filosófica de análise se justifica pela aplicabilidade de seus princípios e conceitos acerca da concepção de mundo, composto por subsistemas nos quais operam a razão instrumental, a razão estratégica e a razão comunicativa.

A prevalência da razão instrumental e do agir estratégico, nos meios políticos e econômicos, acabou por configurar um mundo colonizado (HABERMAS, 1986, p. 78), direcionado a fins individuais em consonância com o modelo neoliberal. Nele, a formação e a prática médica, vinculadas ao mercado de trabalho, à pessoa do médico - inscrita no contexto social e cultural - e às leis do Estado mínimo, desagregam verdades consolidadas, construindo novas perspectivas que se ajustam à conjuntura social e econômica vigente.

Com base nas ideias iluministas, no encontro com uma razão subjetivada, na impossibilidade do retorno às velhas práticas e na possibilidade de encontrar no diálogo uma perspectiva integral do homem, verificou-se em Habermas (1982, 1986, 1987a, 1987b, 1987c, 2007) um elo de convergência entre a medicina essencialmente humanista da antiguidade e a medicina cientificista e fragmentada da atualidade.

Conceitos como iluminismo, racionalização, racionalidade e modernidade tardia (mudança no modo de vivenciar as relaçóes, a partir da identificação da razáo como o elemento ordenador que produz confiança e elimina ou minimiza os riscos) possibilitam a localização temporal, o encadeamento de fatos históricos e, aos poucos, tecem as malhas que fornecem sustentação à configuração do mundo sistêmico habermasiano.

Stotz (1993) assegura que as profissões da área da saúde - com destaque para médicos e enfermeiros - atuam diretamente com seres humanos e convergem suas açôes em prol deles ao visar a prevenção da saúde e a busca da cura para determinadas doenças. Para que isso ocorra esses profissionais 
devem agir e interagir como sujeitos de sua própria vida e com domínio de suas práticas científicas humanizadas, no intuito de transformar a cidadania no exercício de inclusão de cidadãos.

Ressalta-se, desse modo, que o ser humano não é apenas um produto biológico. É, sobretudo, um agente no processo saúde-doença, que vive sua história concreta tendo suas condiçóes de vida determinadas pela sociedade em que se insere. Freire (2017) esclarece que os seres humanos transcendem o biológico, pois são seres histórico-sociais capazes de comparar, valorar, escolher e decidir em razão de sua individualidade e de domínios cognitivos e culturais.

O profissional médico, a nosso ver, assume a responsabilidade histórica pelo engajamento com a realidade que, de acordo com Paulo Freire, tem sua verdade na solidariedade, na competência e na responsabilidade. O autor, Patrono da Educação Brasileira, ressalta:

Posso saber pedagogia, biologia como astronomia, posso cuidar da terra como posso navegar. Sou gente. Sei que ignoro e sei que sei. Por isso tanto posso saber o que ainda náo sei como posso saber melhor o que já sei. E saberei tão melhor e mais autenticamente quanto mais eficazmente construa minha autonomia em respeito à dos outros. (apud COSTA, 1996, p. 94)

A análise da realidade e do contexto formativo dos futuros profissionais médicos revela a notória importância da reflexão sobre o ato comunicativo. Tal ato praticado entre esses atores sociais, associado ao compromisso de compartilhar a assistência à saúde no País, é entendido como um processo de relaçôes individuais, sociais e culturais no qual os profissionais de saúde entrecruzam suas distintas trajetórias e conhecimentos.

\section{O giro linguístico epistemológico: o papel da produçáo, da linguagem e da comunicação}

O devir da razão instrumental subjetiva, reafirma Habermas, passa a existir em decorrência de fatores e movimentos que permitiram a virada paradigmática da subjetividade com o Renascimento, a Revolução 
Francesa e a Revolução Industrial. A historicidade desses movimentos, aperfeiçoados com outras vertentes filosóficas, representadas pelo nominalismo, empirismo e racionalismo, foi importante para a formulação do princípio da subjetividade. Mediante o racionalismo e sua crítica, filósofos como Hegel e Kant estabeleceram formas gerais de pensamento e conhecimento. (FREITAG, 2005; GOMES; SCHRAIBER. 2011; HABERMAS, 1982, 1986, 1987a, 1987b, 1987c, 2007)

No estabelecimento da lógica formal e da lógica transcendental, a primeira proposta por Hegel e a outra por Marcuse (2004, p. 65-66, grifo nosso)) aponta as diferenças, ao esclarecer que:

A Lógica de Hegel expóe a estrutura do ser-como-tal, isto é, as formas mais gerais do ser. A tradição filosófica, desde Aristóteles, designa como categorias os conceitos que compreendem estas formas mais gerais: substância, afirmação, negação, limitação; quantidade, qualidade; unidade, pluralidade etc. A Lógica de Hegel é uma ontologia, pois se liga com tais categorias. Mas esta Lógica trata também das formas gerais do pensamento, do conceito, do juízo e do silogismo e é, sob este aspecto, "lógica formal". Podemos compreender a razão desta heterogeneidade aparente de conteúdo se nos lembrarmos de que também Kant se ocupou de ontologia e de lógica formal na sua Lógica Transcendental, tratando ao mesmo tempo das categorias de substancialidade, causalidade, comunidade (reciprocidade), e da teoria dos juízos.

A distinção tradicional entre a lógica formal e metafísica geral (ontologia) não tem sentido dentro do idealismo transcendental, que concebe as formas do ser como resultado da atividade do entendimento humano. Os princípios do pensamento, portanto, são também princípios dos objetos do pensamento. Nesse processo de ruptura paradigmática com a racionalidade mítica e metafisica, Habermas adota como princípio de negação a lógica transcendental kantiana que, ainda com Marcuse (2004, p. 66), distingue-se bem da lógica hegeliana formal ao assegurar que "a sua concepção desta unidade difere da concepção kantiana. Ele rejeita o idealismo de Kant sob o fundamento de que este admitira a existência de 
'coisas-em-si', à parte dos 'fenômenos', aceitando que tais 'coisas' fossem inapreensíveis, pois, pela razão".

O conceito de razão comunicativa foi desenvolvido por Habermas numa tentativa de descobrir uma concepção de razão situada historicamente - como algo "concretizado na história, sociedade, corpo e linguagem" (HABERMAS, 1986, p. 172) -, mas que, ao mesmo tempo, distancia-se das contingências históricas para criticá-las. Por isso, a racionalidade comunicativa é uma concepção puramente processual da razão, que pressupóe que nenhuma perspectiva concreta pode ser privilegiada com relação à sua racionalidade.

Habermas aponta novos caminhos para a razão, deslocando o fundamento da razão subjetivista para o da intersubjetividade ou dialogicidade. Se o modelo paradigmático da racionalidade moderna tinha como conceito e discernimento a verdade incondicional e o êxito funcional, definidos pela relação meios-fins, o modelo da razão comunicativa, proposto por ele, assenta suas pretensóes de verdade sobre o entendimento intersubjetivo. Assim, Habermas (1982, 1986, 1987a, 1987b) assegura que o poder da razão/reflexão pode ser entendido à medida que os homens conseguirem livrar-se da filosofia da Bewußtsein (consciência ou do sujeito).

A propósito da recuperação da experiência esquecida de reflexão se faz necessária a análise pragmática do uso de linguagem na mediação da interação social. Essa análise tenta revelar "as estruturas gerais da comunicação linguística” (HABERMAS, 1986, p. 137), que são universais e, sobretudo, a possibilidade de uma reflexão crítica, ampliando a análise da razão ao secundarizar a unidade de razão teórica, incluindo as esferas moral-prática e estética. Ao deixar a verdade absoluta subjetivista, a busca de uma verdade exige o uso competente e honesto, daí as implicaçóes ético-morais e os processos argumentativos na procura do que se intitulam acordos consensuados.

De acordo com Habermas (1986, 1987a, 1987b, 1987c, 2007), as comunicaçôes que os sujeitos estabelecem entre si se baseiam em seus esforços de entendimento mútuo num sistema de referências composto de três mundos: o objetivo, o social e o subjetivo. No "mundo objetivo" acontece a representação ou pressuposição de estados e acontecimentos, com base na construção de saberes e conhecimentos. Desse mundo os participantes da comunicação extraem suas interpretaçôes (cultura). $\mathrm{O}$ "mundo 
social" é o lugar de acontecimento da produção ou renovação de relaçóes interpessoais; nele incluem-se as ordens legítimas e a regulamentação da participação dos atores sociais em grupos sociais distintos (sociedade). $\mathrm{O}$ "mundo subjetivo" é o lócus de manifestação de vivências e da autorrepresentação. Nele são configuradas as competências de participação no processo comunicativo e a afirmação da identidade dos atores sociais (personalidade).

Habermas (1982, 1986, 1987a, 1987b, 1987c, 2007) reafirma que a interação entre esses três mundos leva os participantes da situação de comunicação ao entendimento do "Mundo da Vida", que constitui o contexto no qual se desenvolvem os processos de entendimento e os participantes da comunicação se movimentam. O mundo da vida, como nível real do agir comunicativo, exige interpretação. Ele é entendido a partir de uma conjuntura de sentido náo conhecida e, portanto, com possibilidades de abertura a outros horizontes no processo de entendimento. Esse processo se fundamenta, efetivamente, em seus componentes estruturais vinculados à cultura, à sociedade e à personalidade. Esses componentes se atualizam pela instauração dos processos de reproduçáo cultural, social e de socialização. Ao acervo do saber representado pela cultura são acrescentadas as ordens institucionais da sociedade e as estruturas de personalidade, visando à efetivação por "competência" frente à ação comunicativa na totalidade de abordagens possíveis pelos participantes da interaçáo.

Carrolo (1997, p. 26), ao desenvolver estudos sobre a construção da identidade profissional, evidencia que a "ontogênese do indivíduo não é senão um permanente processo de interação comunicativa." $\mathrm{O}$ autor também recorre à contribuição habermasiana, que estabelece os fundamentos, os mecanismos e as dimensóes de um novo paradigma, que busca a ruptura com a razão transcendentalizada, de formação entendida como socialização profissional. Está fundamentada na Teoria do Agir Comunicativo, que propóe mudanças conceituais.

Conforme Carrolo (1997, p. 28, grifo nosso), o processo de socialização é constituído "pela unidade dialética de três mediaçóes entre o sujeitoator e o objeto mundo: $1^{\circ}$ - o Processo de Trabalho (Agir Instrumental); $2^{\circ}$ - a Representação Simbólica (Linguagem); $3^{\circ}$ - a Interação Recíproca (Agir Comunicativo)." 
Em face desse processo de socialização, Habermas (1987a) afirma que em cada contexto social surge uma nova forma de vida disposta e capaz de inclusão, caracterizada pela intersubjetividade, que torna possível o agir comunicativo. $\mathrm{O}$ instrumento dessa expressão de intersubjetivação é a própria linguagem, que cria o sistema de orientação supra subjetiva dos indivíduos integrados à sociedade e pertencentes às instituiçôes sociais. Assim, Carrolo (1997, p. 28) declara que o agir comunicativo

distingue-se do agir instrumental, na medida em que não visa apenas finalidades técnicas ou organizativas, mas estrutura a interação entre os indivíduos numa relação global e completa: ação e comunicação. Embora Habermas afirme a autonomia irredutível dos três mecanismos da socialização, só o agir comunicacional permite a formação das identidades sociais, de que a identidade profissional é caso específico.

As identidades sociais como Lebenswelt (mundo vivido) não podem reduzir-se a sistemas de trabalho, nem a sistemas de integração, embora eles sejam elementos constitutivos da socialização e da legitimação da "competência" comunicativa (mundo dos sistemas - razão normativa).

Quanto ao sistema ou mundo sistêmico, ele se confronta com o mundo da vida e se mantém dependente do agir comunicativo, pois o mundo sistêmico é decorrente da racionalização do mundo da vida. $\mathrm{O}$ mundo do sistema surge como normatizador que interfere no agir comunicativo em face de mecanismos de controle social. Quando o mundo sistêmico fica independente do mundo da vida, torna-se mais complexo e passa a se impor sobre ele. Habermas (2007) nomeia "colonização do mundo da vida” àquele que passa de um sistema central para um sistema periférico.

$\mathrm{Na}$ contemporaneidade, no que se refere às relaçóes do trabalho coletivo, o mundo vivido envolve uma série de níveis, quais sejam: o campo de investimento de trabalho; a organizaçáo do comportamento relacional e inter-relacional; os valores que surgem ou ressurgem da interação comunicacional; e a transmissão de conhecimentos - processo de ensinagem (ACIOLE, 2004). Esse processo educativo de integração social é a forma transformadora que promove a socialização do sujeito com a possibilidade de inserção social do "outro". (HABERMAS, 1982, 2007) 


\section{Entendimento linguístico: possibilidades de mudanças no processo educativo}

Para realizar a proposta dos usos da linguagem como modelo de investigação alicerçado na competência comunicativa, Habermas póe em evidência dois critérios: a competência linguística e a realização. $\mathrm{O}$ autor (1987a, p. 321) entende que existe sentido em investigar as propriedades fonéticas, sintáticas e semânticas das orações no marco de uma reconstrução da competência linguística e deixar as propriedades pragmáticas das emissóes para uma teoria da realização linguística.

Essa competência comunicativa (Kompetenz und Realisierung) consiste no domínio não reflexivo, pré-teórico, de certas pressuposições que acompanham o entendimento linguístico. Por isso, pode ser reconstruído racionalmente numa perspectiva universalista (ANASTASIOU, 2003). Reafirmando a perspectiva universalista e transcendental, Boufleuer (2001, p. 3) ressalta que

pelo agir comunicativo é possível transcender a consciência ingênua onde o saber se apresenta como um conjunto de conhecimentos absolutos, abstratos com uma relação apriorista com a realidade. Essa transcendência vai permitir que os sujeitos educativos compreendam o saber racional, criados por indivíduos enlaçados em procedimentos indutivos, dedutivos e analógicos que se submetem constantemente a um critério de verdade. Isto circunscreve sua historicidade uma vez que incorpora o saber anterior enquanto etapa necessária de sua gênese. A ausência de dogmatismos dado que é constantemente superado. Sua fecundidade no sentido de que é sempre gerador de outro conhecimento.

Com a superação da consciência ingênua mediante o ato educativo, o sujeito poderá se emancipar, como consequência de um processo dialético que oscila entre o consenso e o dissenso, conforme a Teoria do Agir Comunicativo. Pressupóe-se, então, que as atividades e dinâmicas existentes na instituiçãao escolar podem ser açóes correspondentes ao agir orientado pelo produto (ação instrumental e ação estratégica) ou açóes orienta- 
das pelo entendimento (ação comunicativa) (HABERMAS, 1987a). Essas açóes são realizadas, no espaço escolar, pelos alunos e pelos professores na condição de participantes do processo educativo.

O homem como sujeito, para Habermas (2007), só existe inserido em comunidade, de tal modo que seu agir é sempre um agir individual e social. A conquista da educação do ser humano passa pela configuração do mundo histórico, capaz de gerar a autonomia do sujeito: o homem se faz educado, construindo mundos em que a educação se efetiva na configuração de suas relaçôes intersubjetivas. Entre essas relações, a médico-paciente é o eixo norteador das políticas de formação dos profissionais de saúde.

\section{A razão comunicativa na (re) definição da relaçáo médico-paciente}

Compreende-se que, dentre os estudos desenvolvidos por Habermas (1982), a razão comunicativa destranscentalizadora é uma fonte fértil para as iniciativas de rompimento, de encorajamento de (re) conceituação da razão, como força ideológica e produtiva. Nesse sentido, a liberdade colocarse-á como eixo central de mudança paradigmática por meio da superação pela linguagem.

O diálogo, de acordo com o autor, somente existe com o conhecimento das diferenças, que estáo ligadas ao fato de que cada um dos sujeitos desenvolve suas reflexôes em contextos diferentes de vida e de ação. A comunicação e o diálogo se estabelecem entre aqueles atores sociais que não renegam uns aos outros o direito de suas próprias palavras, pensamentos e decisões. Habermas (1982) enfatiza que o agir comunicativo é um processo circular, no qual um ator social é o iniciador que domina as situaçóes, por meio de suas açóes, e produto das tradiçóes, da cultura e dos processos de socialização, entre eles o ato médico.

A relação interativa estabelecida entre o médico e o paciente durante o ato médico, e seus respectivos compromissos sociais, devem ser desenvolvidos com base no agir comunicativo. Nesse tipo de relação não poderá ocorrer o predomínio hegemônico de quem domina a ciência (o médico) sobre o leigo (o paciente). Essa relação deve ser marcada pela ética profissional de respeito mútuo e confiança entre ambos os sujeitos, de modo que 
impere a racionalidade comunicativa do médico com o paciente, consideradas as limitaçôes deste, e não somente uma fala unívoca de quem detém o conhecimento.

Como um fio condutor, a relação médico-paciente se faz presente direta ou indiretamente nas 28 competências elencadas nas DCN de 2001 e enaltecidas em 2014, favorecendo a correlação entre as categorias trabalho, interação, poder, mundo do sistema e mundo da vida com um conjunto de determinaçóes estabelecidas pelas DCN. Nesse movimento, emerge a necessidade de contrapor as relaçóes humanas e a racionalidade normativa na construção e re(construção) de um cenário ideal ou utópico, com vistas à formação de um profissional da saúde (cf. Tabela 1).

A comunicação e argumentação como forma de liderança pertencem ao mundo do sistema para Habermas, em função da razão normativa na qual predominam as leis e os códigos de ética profissionais. Contudo, a proposta habermasiana aponta para uma liderança com compartilhamento de poder, permitindo o empoderamento dos atores sociais envolvidos na relação médico-paciente, assim como os profissionais da saúde que atendem o mesmo paciente e, em especial, a sua família.

As mudanças no mundo da vida podem ser legalizadas pelo próprio mundo objetivo e subjetivo, com transformaçôes sociais importantes até mesmo quanto à promoção de estilos de vida saudáveis e à integraçáo comunitária, todavia legitimados pelo mundo do sistema (normas e códigos de referência ética).

A formação médica precisa promover a competência comunicativa, pelo menos em dois sentidos, quais sejam: trazer para o diálogo a questão da intersubjetividade entre os profissionais de saúde; promover o entendimento no tratamento e cuidado do paciente, ao buscar um consenso que favoreça a igualdade entre profissionais e o respeito ao paciente.

Para lidar com a dinâmica do mercado de trabalho, as políticas públicas de saúde e manter-se atualizado com a legislação em saúde, o acadêmico de medicina deve buscar o entendimento do mundo objetivo, ou seja, da realidade concreta. Assim, os futuros profissionais da saúde devem estar capacitados do ponto de vista argumentativo diante de poderes instituídos - Executivo, Legislativo e Judiciário -, na promoçáo de açóes democráticas e participativas em defesa dos direitos do próprio mundo objetivo, visando a sua transformação pela linguagem. 
As decisóes dos profissionais de saúde linguisticamente competentes, legalizadas pela tessitura social esgarçada em que vivem, adquirem uma especial forma de poder participativo e compartilhado, ao mesmo tempo em que humanizam o humano fragmentado não só pela técnica $\mathrm{e}$ pela tecnologia, mas sobretudo pelas relaçôes humanas.

\begin{tabular}{|c|c|}
\hline $\begin{array}{c}\text { Competências - diretrizes nacionais } \\
\text { curriculares para o curso de medicina - } \\
2001-2014\end{array}$ & $\begin{array}{c}\text { Categorias do agir } \\
\text { comunicativo habermasiano }\end{array}$ \\
\hline $\begin{array}{l}\text { Comunicaçáo e argumentaçáo para tomada } \\
\text { de decisôes, liderança, administraçáo e } \\
\text { gerenciamento. }\end{array}$ & $\begin{array}{l}\text { Trabalho, interação e poder. } \\
\text { Mundo do sistema. }\end{array}$ \\
\hline $\begin{array}{l}\text { Promover estilos de vida saudáveis, } \\
\text { conciliando as necessidades tanto dos } \\
\text { seus "clientes"/pacientes quanto às de sua } \\
\text { comunidade, atuando como agente de } \\
\text { transformaçáo social. }\end{array}$ & $\begin{array}{l}\text { Mundo da vida. } \\
\text { Trabalho, interação e poder. }\end{array}$ \\
\hline $\begin{array}{l}\text { Comunicar-se adequadamente com os } \\
\text { colegas de trabalho, os pacientes e seus } \\
\text { familiares. }\end{array}$ & $\begin{array}{l}\text { Mundo da vida (sistema, } \\
\text { objetivo e subjetivo). }\end{array}$ \\
\hline $\begin{array}{l}\text { Lidar criticamente com a dinâmica do } \\
\text { mercado de trabalho e com as políticas de } \\
\text { saúde. }\end{array}$ & $\begin{array}{c}\text { Mundo objetivo e subjetivo. } \\
\text { Trabalho. }\end{array}$ \\
\hline $\begin{array}{l}\text { Considerar a relaçáo custo-benefício nas } \\
\text { decisôes médica, levando em conta as reais } \\
\text { necessidades da populaçáo. }\end{array}$ & Mundo objetivo. \\
\hline Atuar em equipe multiprofissional. & Trabalho, interação e poder. \\
\hline $\begin{array}{l}\text { Manter-se atualizado com a legislaçáo } \\
\text { pertinente à saúde. }\end{array}$ & Mundo do sistema. \\
\hline
\end{tabular}

Quadro 1: Correlaçáo entre competências das DCN e categorias do agir comunicacional habermasiano

Fonte: o proprio Autor.

As práticas nas relaçóes entre médico e paciente, de modo geral, são orientadas pela racionalidade instrumental ou manipuladora, caracterizada, em particular, pela postura autoritária de quem detém o poder, o saber 
e o direito de argumentar sem contra argumentaçáo, enquanto o "cliente" (expressão própria do mercado) pacientemente ouve e recebe hipóteses diagnósticas e condutas terapêuticas.

A argumentação habermasiana indica que a análise dos diversos tipos de atividades realizadas pelos professores e estudantes, em uma escola de formação de profissionais da saúde, tem o objetivo de reconhecer indicadores da existência de açóes educativas, entre elas aquelas cujo caráter se aproxima do agir comunicativo, do agir orientado pelo entendimento e que visa a obtenção do consenso. A imagem organizacional da escola (CARROLO, 1997) como democrática e livre representa algo desejável, embora diante de uma racionalidade transcendental e não crítica não consiga ultrapassar o autoritarismo; alcança-se, de fato, o agir instrumental manipulador.

Com efeito, a escola carrega junto de si uma dupla característica ao mesmo tempo em que, por um lado, é transformadora da realidade à medida que educa as novas geraçóes para buscarem no mundo da vida novas formas coletivas de vivência, de experiências e de realizaçôes pessoais e, por outro, é coercitiva. Como instituição social, muitas vezes adota uma gestão organizada com o objetivo de ser um espaço para a realização de ações estratégicas típicas do mundo sistêmico.

A escola médica e os espaços comunitários de atenção primaria têm um importante papel no desenvolvimento das aprendizagens necessárias para que, primeiro como sujeito e, depois, como grupo social, o ser humano possa atuar com um nível maior de racionalidade comunicativa e ética, de acordo com o artigo.

A ética do discurso apoia-se em outras ciências reconstrutivas, mesmo que exclusivamente hipotéticas, para as quais é necessário buscar no futuro confirmaçóes plausíveis. Uma dessas ciências reconstrutivas é a teoria do desenvolvimento da consciência moral, de L. Koklberg (HABERMAS, 1982). Para Habermas (1982, p. 143-144) e de acordo com essa teoria:

o desenvolvimento da capacidade de julgar moral efetua-se da infância até a idade adulta passando pela adolescência, segundo um modelo invariante; o ponto de referência normativo da via evolutiva analisada empiricamente é constituído por uma moral guiada por princípios: nela a ética do discurso pode se reconhecer sem seus traços essenciais. 
A construção do mundo do aluno é uma reprodução do mundo realizado antes pelos docentes. Ambos são mediados por um objeto que deve ser aprendido, legitimado pela razão monológica. As tendências pedagógicas tradicionais propóem um único saber válido, verdadeiro, acrítico. Habermas explica que se a relação do conhecimento fosse colocada no mundo da vida, na continuidade de cada sujeito, náo para permanecer nela, mas para, a partir dela, voltar criticamente ao objeto, então a assimetria e a desigualdade entre os interlocutores desapareceriam.

\section{Consideraçóes finais}

É importante recolocar a questão da educação médica e, especialmente, da instituição escolar como o espaço em que a ação comunicativa, por meio da relação dialógica, suscite uma nova intersubjetividade, ao mesmo tempo em que estimule uma reflexão crítica sobre a realidade concreta a ser transformada.

O caminho a ser percorrido é o da valorização das relaçóes humanas face a face, no qual a razão do "outro" expressa-se como não colonizada. É indispensável que se realize um encontro clínico de "proximidade", em que a dignidade do paciente está na origem e constitui a própria possibilidade de construir e (re) construir uma relação argumentativa e dialógica na busca de consensos.

É estabelecida, ainda, como característica a ser desenvolvida, a visão global do ser humano. Nas relaçóes humanas, vividas na contemporaneidade, Habermas (1987a), por meio da teoria do agir comunicativo, propóe a inclusão do outro, sob a perspectiva de ampliação da razáo pela intersubjetividade, e a leitura do mundo da vida, ainda que essa inclusáo seja simples convicção da possibilidade do dissenso. Tornar-se um médico crítico e reflexivo também implica proporcionar ao paciente a capacidade de, nessa busca de entendimento, ter voz participante no diálogo.

A relação humanizadora do médico com o paciente e com seus familiares, a visão inovadora no exercício da atividade médica, a capacidade de trabalhar em equipe multiprofissional, a participação em processos de gerência de políticas e serviços de saúde e preocupações como a formação continuada são prerrogativas fundamentais para um exercício profissio- 
nal socialmente qualificado são preconizadas pelas DCN e ancoradas na Teoria do Agir Comunicativo.

Nas atuais circunstâncias não é fácil abstrair-se da presença dos "outros”, dos pobres, dos marginalizados, dos oprimidos. Pode-se propor, com clareza, açôes educacionais para formação médica que visem atenuar as diferenças sociais em contextos sociopolíticos cada vez mais diferenciadores. A consciência crítica do poder ideológico e sedutor da ciência e tecnologia, perante a fragmentação do homem e o fortalecimento do mercado, é o caminho para a atuação ético-moral no cuidado da sociedade.

\section{Referências}

ACIOLE, G. G. O lugar, a teoria e a prática profissional do médico: elementos para uma abordagem crítica da relação médico-paciente no consultório. Interface, v. 8, n. 14, p. $95-112$, fev. 2004.

ANASTASIOU, L. C.; ALVES, L. P. Processos de ensinagem na Universidade. Joinville, SC: Univille, 2003.

BOUfLEUER, J. P. Pedagogia da ação comunicativa: uma leitura de Habermas. Ijuí, RS: Unijuí; 2001.

BRASIL. Ministério da Educação. Conselho Nacional de Educação. Câmara de Educação Superior. Resoluçáo CNE/CES no 4, de 7 de novembro de 2001. Institui Diretrizes Nacionais Curriculares do Curso de Graduação em Medicina. Diário Oficial da União, Brasília, 9 de novembro de 2001. Seção 1, p. 38.

BRASIL. Ministério da Educação. Conselho Nacional de Educação. Câmara de Educação Superior. Resolução CNE/CES no 3, de 13 de janeiro de 2014. Institui Diretrizes Nacionais Curriculares do Curso de Graduação em Medicina. Diário Oficial da Uniāo, Brasília, 20 de junho de 2014. Seção 1, p. 38.

CARROLO, C. L. Decadísmo e simbolismo no Brasil. Rio de Janeiro: Livros Técnicos e Científicos; 1997.

COSTA, J. As imagens organizacionais da escola. Lisboa, Portugal: ASA Editores, 1996.

FREIRE, P. Pedagogia do oprimido. Rio de Janeiro: Paz e Terra, 2017.

FREITAG, B. Dialogando com Jürgen Habermas. Rio de Janeiro: Tempo Brasileiro, 2005. 
GOMES, R. M.; SCHRAIBER, L. B. A dialética humanização-alienação como recurso à compreensão crítica da desumanização das práticas de saúde: alguns elementos conceituais. Interface - Comunicação, Saúde, Educação, v. 15, n. 37, p. 339-350, abr./jun. 2011.

HABERMAS, J. A inclusão do outro: estudos de teoria política. São Paulo: Editora Loyola, 2007.

Verso, 1986.

Autonomy and solidarity: interviews with Jürgen Habermas. London: Ed.

. Conhecimento e interesse. Trad. José N. Heck. Rio de Janeiro: Zahar, 1982.

. Técnica e ciência como ideologia. Lisboa: Ediçôes 70, 1987a.

. Théorie de l'agir communicationnel. Tome premier: rationalité de l'agir et rationalisation de la société. Traduit de l'allemand par Jean-Louis Schegel. Paris: Fayard, 1987b.

. Théorie de l'agir communicationnel. Tome second: critique de la raison fonctionnaliste. Traduit de l' allemand par Jean-Louis Schegel. Paris: Fayard, 1987c.

MARCUSE, H. Razão e revolução: Hegel e o advento da teoria social. São Paulo: Paz e Terra, 2004.

STOTZ, E. N. Enfoque sobre educação e saúde. In: VALLA, V. V.; STOTZ, E. N. (Org.). Participação, educação popular e saúde: teoria e prática. Rio de Janeiro: RelumeDumará, 1993. p. 13-21.

Recebido em 2 jun. 2018 / Aprovado em 29 out. 2018

\section{Para referenciar este texto:}

MENEZES JUNIOR, A. S.; BRZEZINSKI, I. A teoria do agir comunicativo e a formação médica: análise crítica das competências curriculares e da relação médicopaciente. EccoS - Revista Científica, São Paulo, n. 47, p. 44I-456. set/dez. 2018. Disponível em: <https://doi.org/I0.5585/EccoS.n47.8757>. 